\title{
Deformation analysis of deep foundation pit excavation in China under time-space effect
}

Qingwei Zhang MSC

Lecturer, School of Civil Engineering and Architecture, Anyang Normal

University, Anyang, China (erqw016188@sina.cn)

The excavation of a deep foundation pit often causes deformation, so it is of great value to analyse the issue. In this study, the space-time effect of foundation pit deformation was introduced, and then the deformation of a deep foundation pit in Anyang, China, was monitored and analysed. The results showed that the displacement of the foundation pit enclosure structure increased gradually with the progress of the project, and there was a gap between the displacement values of different parts. The maximum displacement at the middle point of the long side was $13 \mathrm{~mm}$, and that of the corner was only $5 \mathrm{~mm}$. The vertical displacement of the surrounding buildings increased with the progress of the project, and the displacement value near the corner of the foundation pit was relatively small. The closer the surrounding pipelines were to the middle point of the foundation pit, the larger the displacement value was, and the displacement value also increased with the progress of the project. The results of this study show that the deformation of a deep foundation pit accords with the time-space effect, which provides some references for the deformation analysis of deep foundation pit engineering.

\section{Introduction}

With the rapid development of society, the process of urban construction has sped up (Hu, 2017), and the number of buildings on the ground are increasing and the land resources are declining. Therefore, several types of underground buildings have appeared, such as underground subways, parking lots and shopping malls. Deep foundation pit excavation is an important part of underground engineering construction. In the process of urban deep foundation pit excavation, with the progress of the project, the land around the foundation pit easily deforms due to the complex surrounding construction environment (Zhang et al., 2015c), which will cause displacement changes in the surrounding surface and even cracking of the surrounding pavement, house collapse, water inrush (Wang et al., 2016) and so on. Therefore, the analysis of deep foundation pit deformation is necessary.

On the one hand, the time-space effect refers to the space effect. In the process of excavation, the deformations of different parts are different because of the different pressures. On the other hand, the time-space effect refers to the time effect. With the progress of the project, the deformation of the foundation pit will gradually increase. The space-time effect has a great influence on the deformation of the foundation pit. By considering the space-time effect, the size of excavation and the type of support are determined, which play a great role in controlling the deformation of the foundation pit.

Among the current studies, Zhang et al. (2015a) analysed the deformation of the foundation pit excavation of Metro line 1 in Xuzhou, China and discussed the influence of the distance between the foundation pit and the river on the excavation. The results showed that the closer the foundation pit was to the river, the greater the difference in the horizontal displacement between the two sides of the foundation pit. Zhang and Liu (2018) analysed a foundation pit project in China's Liaoning Province. Through numerical simulation, they found that the horizontal displacement of the pile anchor position structure gradually increased with the increase in excavation depth, and the maximum horizontal displacement was at a position that had some distance from the top of the pile. If the internal friction and cohesion of the soil were large, the horizontal displacement of the supporting structure was small. Ye et al. (2018) studied the foundation pit of a Lanzhou, China subway station and found from the monitoring data that the horizontal and vertical displacements of the pile top increased gradually and the axial force of the steel support tended to be stable with the excavation of the foundation pit. Zhang et al. (2015d) monitored a foundation pit project in Shanghai, China and found that the settlement value of adjacent buildings gradually increased with the progress of the project; the structural settlement was large due to the long-time excavation of the fourth layer of soil and the removal of the support would also slightly increase the settlement value of the building. Through the establishment of the multiple adaptive regression spline (Mars) model, Zhang et al. (2017a) realised the inverse parameter identification of the soil relative stiffness ratio and the inverse parameter estimation of wall system stiffness in the process of deep foundation pit excavation, and found through the experiment that the values obtained by the Mars model were consistent with the field records. Wang et al. (2014) designed a probability analysis method for deep foundation pit excavation based on the maximum likelihood formula, and found through case analysis that the method could effectively predict the response of the wall and adjacent buildings in the excavation process, so as to evaluate the damage potential of buildings in the excavation stage.

Ong and some other researchers carried out multi-aspect analyses of the soil movement induced by excavation, including a study on the behaviour of a pile under the excavation-induced lateral 
movement of soil (Ong et al., 2003b), a study on the pile response caused by the excavation-induced clay movement (Ong et al., 2003a), a study on deep foundation pit finite-element modelling using two-dimensional finite-element software (Sage Crisp version 5.1 and Plaxis version 8.2) (Ong et al., 2006) and a field study on an in situ deep foundation system in Kuching, Sarawak, Malaysia (Ong and Choo, 2011).

Taking a deep foundation pit in Anyang City, China as an example, this study performed a simple analysis of the deformation of a foundation pit under the effect of time and space, in order to provide some scientific references for the smooth progress of the project. At present, in the research of deep foundation pits, the analysis of their time-space effect is seldom encountered. The research results of this study verified that the deformation law in the process of deep foundation pit excavation conformed to the characteristics of the time-space effect. Therefore, in a deep foundation pit project, the time-space effect should be fully considered and the reasonable support structure and excavation method should be selected, so as to realise the safety of the project.

\section{Foundation pit deformation under the effect of time and space}

With the excavation of the foundation pit, the pressure difference between the soil inside and outside the foundation pit results in the displacement of the soil inside and outside the pit. Moreover, the pressure of the soil outside the pit bottom causes the soil at the bottom of the foundation pit to press upwards, resulting in the uplift of the pit bottom (Xu et al., 2017). Around the urban deep foundation pit project, there are many kinds of pipelines, such as those of gas and water ( $\mathrm{Li}$ et al., 2017), so the deformation of the foundation pit needs special attention.

Under the effect of time and space, the influence on the enclosure structure of the foundation pit is the largest. As shown in Figure 1, there is displacement similar to a parabola on both sides of the enclosure structure, in which the displacement in the corner area is small due to the support in two directions, while the displacement in the centre of the foundation pit is large.

Under the effect of time and space, the land outside the foundation pit experiences settlement (Yang et al., 2015b). The

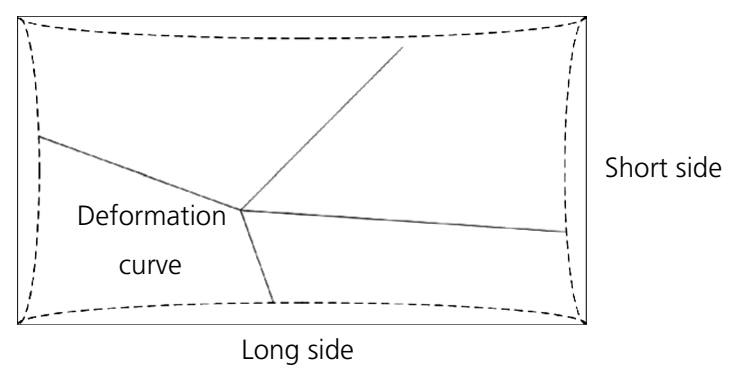

Figure 1. Deformation of the enclosure structure closer the surface is to the enclosure structure, the larger the settlement value is. The farther away it is from the enclosure structure, the smaller the settlement value is, and the settlement value will increase with the excavation.

On the one hand, the deformation of foundation pit is affected by geology and hydrology; on the other hand, it is also affected by the construction method and support structure. For a foundation pit with poor geology, the deformation and settlement are also large. When excavating, the process of supporting first and then excavating is also more conducive to controlling the deformation of the foundation pit.

\section{Project overview}

Taking a deep foundation pit project in Anyang City, China (Figure 2), as an example, the total area was $62458 \mathrm{~m}^{2}$, the overground area was $40000 \mathrm{~m}^{2}$, the underground area was $22458 \mathrm{~m}^{2}$, the area of the foundation pit was $7564 \mathrm{~m}^{2}$ and the maximum excavation depth was about $11.3 \mathrm{~m}$. The surrounding environment was relatively complex. The east side was close to the business district. The south side was a road, and the municipal pipeline was buried under the road. The north side was close to a residential building. On the west side was open space. According to the field survey, the upper layer of the engineering geology was a soil layer and the lower layer was a rock layer. See Table 1 for details.

The project adopted the open-excavation and cut-bottom-up method, which is divided into three layers of excavation, -3.5 , -7.5 and $-11.5 \mathrm{~m}$. The construction process is shown in Table 2, and the adopted enclosure structure is shown in Figure 3.

The deformation of the foundation pit was monitored using a TGCX-1-100B inclinometer, including the horizontal displacement of the enclosure structure, the vertical displacement of the surrounding buildings and the displacement of the surrounding pipelines.

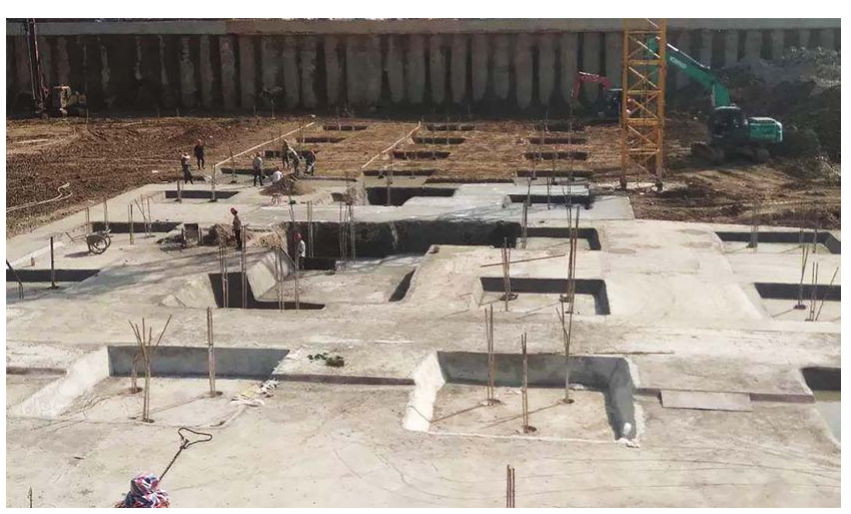

Figure 2. Scene picture of the deep foundation pit project 
Table 1. Overview of engineering geology

\begin{tabular}{llccrrr}
$\begin{array}{l}\text { Number of } \\
\text { stratum }\end{array}$ & \multicolumn{1}{c}{ Lithology name } & Thickness: $\mathbf{m}$ & $\begin{array}{c}\text { Unit weight: } \\
\mathbf{k N} / \mathbf{m}^{\mathbf{3}}\end{array}$ & $\begin{array}{c}\text { Poisson's } \\
\text { ratio }\end{array}$ & $\begin{array}{c}\text { Cohesion: } \\
\mathbf{k P a}\end{array}$ & $\begin{array}{c}\text { Frictional } \\
\text { angle: }\end{array}$ \\
1 & Miscellaneous fill & 0.62 & 17.50 & 0.38 & 0 & 80 \\
2 & Silty clay & 0.62 & 18.50 & 0.31 & 28 & 25 \\
3 & Pebble & 1.13 & 18.29 & 0.22 & 0 & 38 \\
4 & Breccia & 0.78 & 19.31 & 0.31 & 5 & 32 \\
5 & Strongly weathered mudstone & 3.13 & 21.36 & 0.22 & 80 & 25 \\
6 & Moderately weathered mudstone & 2.62 & 22.48 & 0.23 & 100 & 26 \\
7 & Strongly weathered sandstone & 2.74 & 23.69 & 0.21 & 200 & 27 \\
8 & Moderately weathered sandstone & 4.81 & 25.78 & 0.19 & 400 & 25 \\
9 & Strongly weathered conglomerate & 2.62 & 26.46 & 0.18 & 450 & 33 \\
10 & Moderately weathered & 9.17 & 27.28 & 0.21 & 500 & 40 \\
& conglomerate & & & & &
\end{tabular}

Table 2. Construction process of the deep foundation pit

\begin{tabular}{ll} 
Stage & Explanation \\
\hline 1 & Excavation of the first layer is completed \\
2 & Excavation of the second layer is completed \\
3 & Excavation of the third layer is completed \\
4 & Concrete base slab is completed \\
5 & Main structure is completed
\end{tabular}

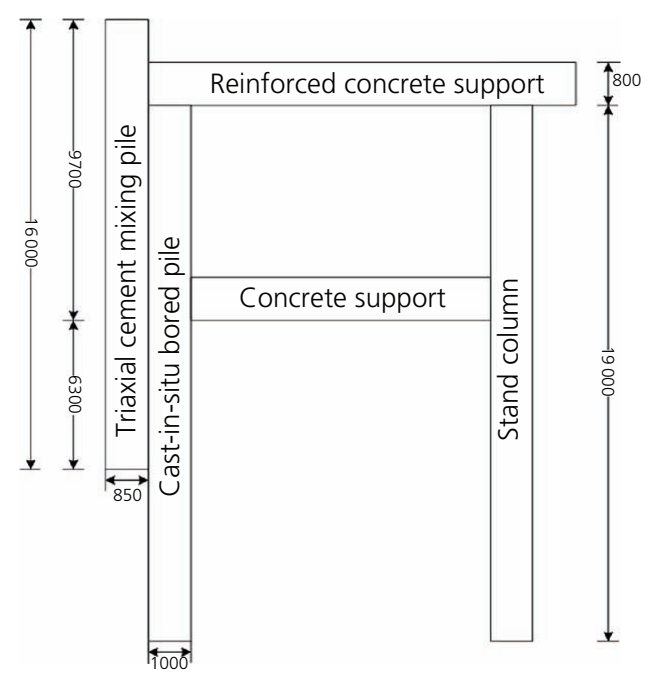

Figure 3. Profile of the enclosure structure (dimensions in $\mathrm{mm}$ )

\section{Foundation pit deformation monitoring results}

Horizontal displacement of the enclosure structure

Taking the monitoring points at the corner of the enclosure structure and the middle point of the long side as examples, the horizontal displacement of the enclosure structure was analysed, and the results are shown in Figures 4 and 5.

It is seen from Figures 4 and 5 that the displacement change rules of the two monitoring points were basically similar. With the progress of the project, the horizontal displacement increased first and then decreased, and the displacement value increased with
Horizontal displacement: $\mathrm{mm}$

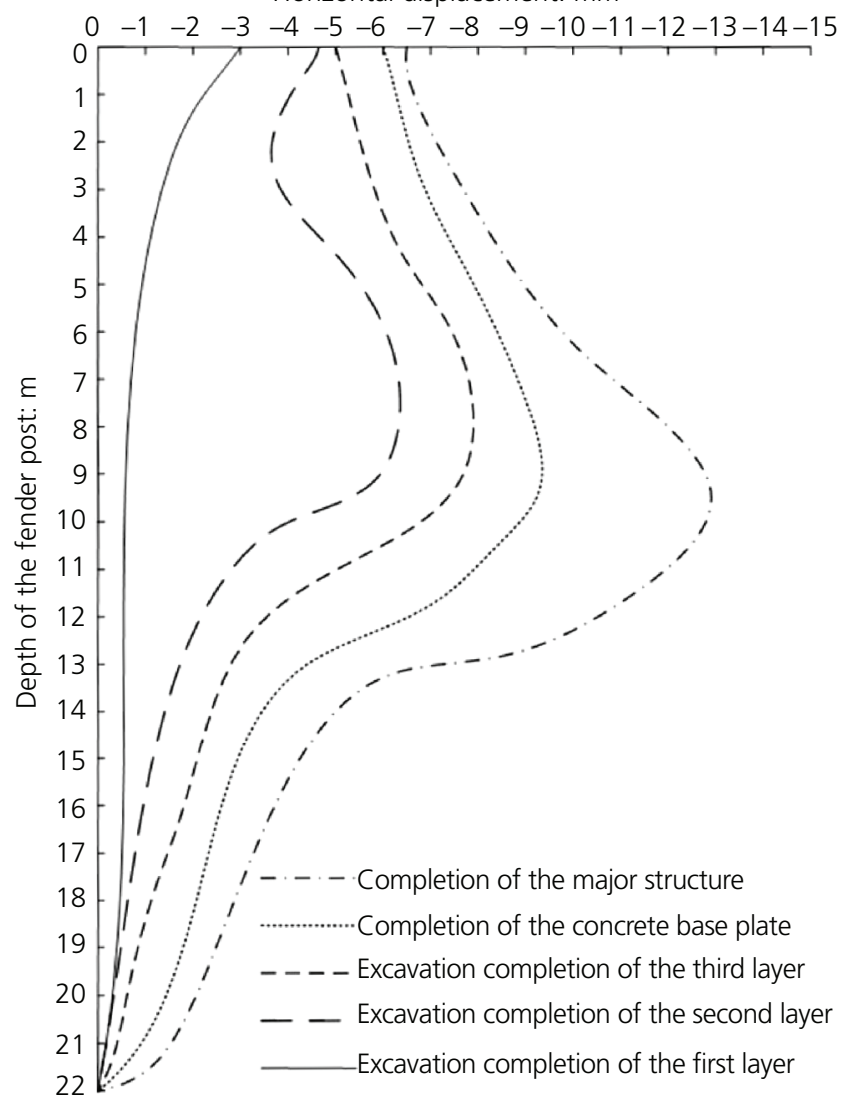

Figure 4. Horizontal displacement of the middle point of the long side

time. The maximum displacement of the middle point of the long side was about $13 \mathrm{~mm}$, and the maximum displacement of the corner was about $5 \mathrm{~mm}$. The comparison between Figures 4 and 5 suggested that the displacement value of the corner of the enclosure structure was obviously smaller than that of the middle point of the long side, which was due to the enclosure structure on both sides of the monitoring point having strong constraining force under the effect of time and space. 
Deformation analysis of deep foundation pit excavation in China under time-space effect

Zhang

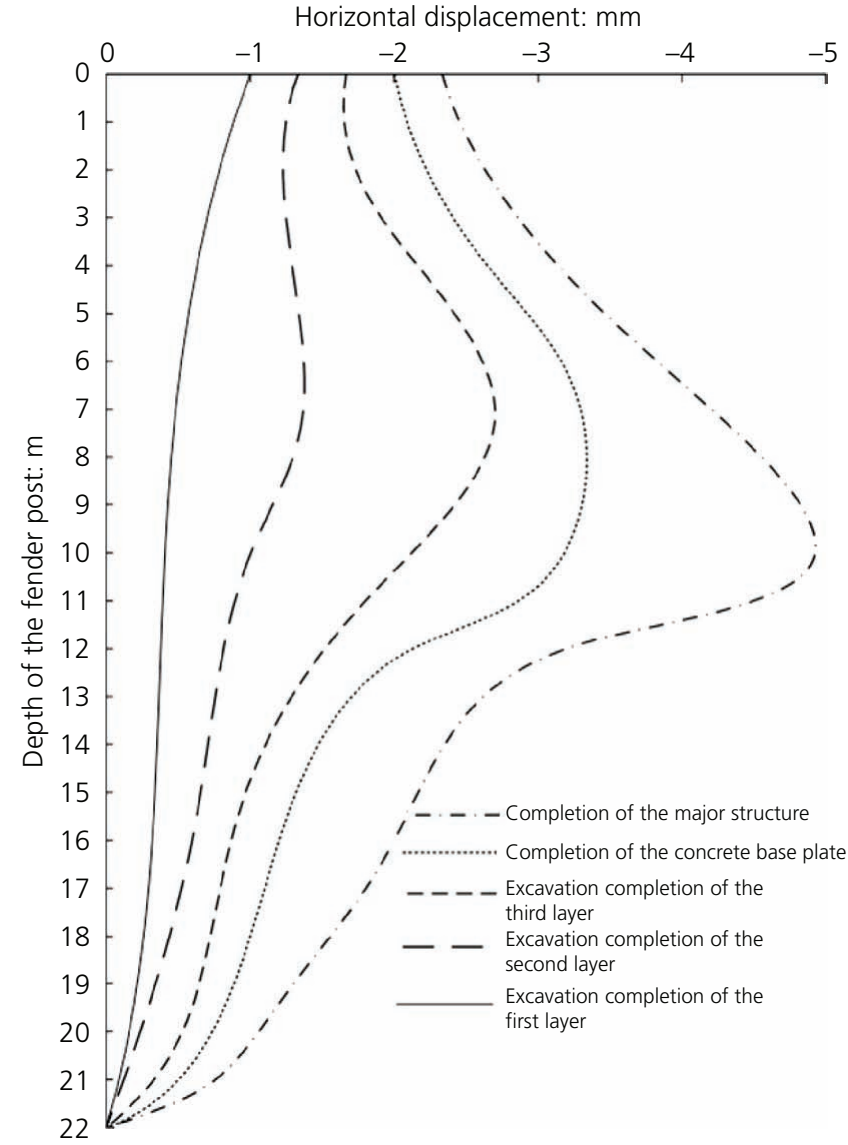

Figure 5. Horizontal displacement of the corner

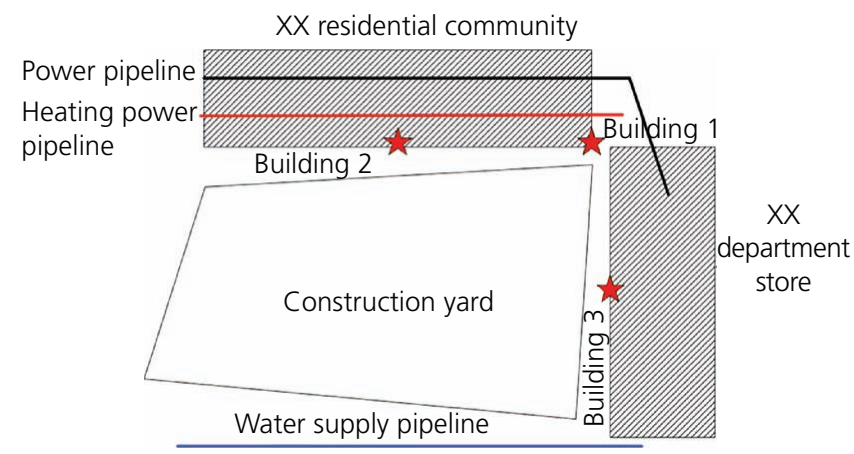

Figure 6. Schematic diagram of the monitored buildings

\section{Vertical displacement of the surrounding buildings}

The north side of the foundation pit was close to a residential building, and the east side was close to a commercial area. Building 1 , which was close to the corner of the foundation pit; building 2, which was close to the midpoint of the north side of the foundation pit; and Building 3, which was close to the midpoint of the east side of the foundation pit, were selected for vertical displacement analysis (Figure 6). The results are shown in Figure 7.

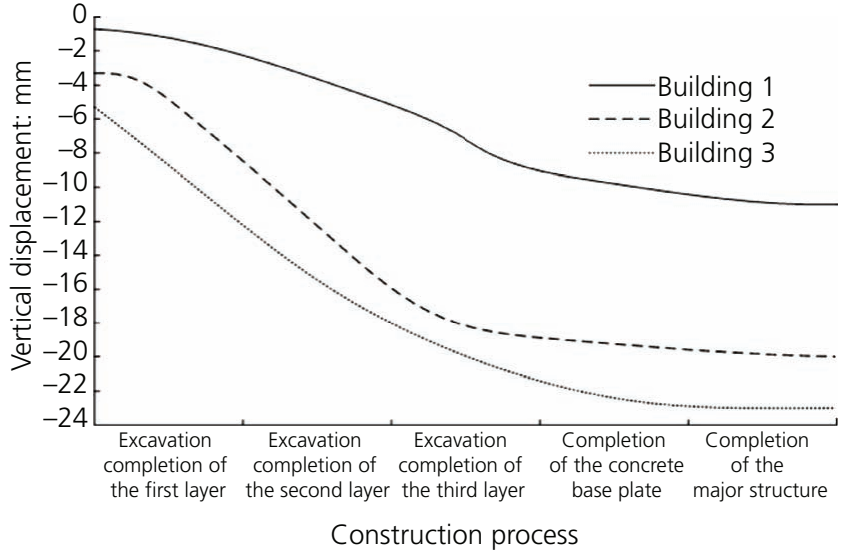

Figure 7. Vertical displacement of the surrounding buildings

It is seen from Figure 7 that the vertical displacement values of the buildings around the foundation pit increased with the progress of the project. The comparison between buildings demonstrated that the displacement value of building 1 was the smallest, with a maximum displacement of $10 \mathrm{~mm}$, and the displacement value of building 3 was the largest, with a maximum displacement of $23 \mathrm{~mm}$. As the position of building 1 was close to the corner of the foundation pit, under the effect of the arch angle, the influence was small. The space effect on buildings 2 and 3 was large, so the displacement values were also large.

\section{Displacement of the surrounding pipelines}

The displacements of a power pipeline, a water supply pipeline and a thermal pipeline near the foundation pit (Figure 6) were analysed, and the results are shown in Figures 8 and 9.

It is seen from Figure 8 that the displacement of pipelines around the foundation pit was basically parabolic: the closer the pipelines

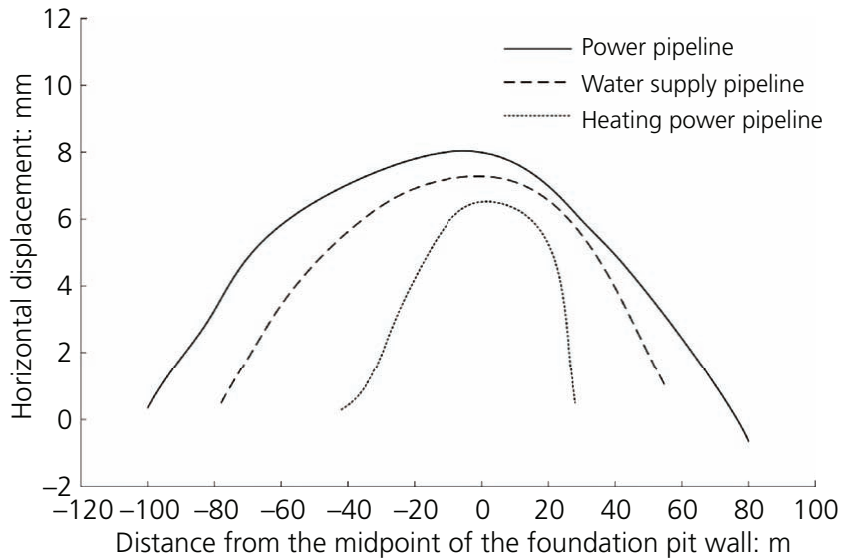

Figure 8. Displacement of the surrounding pipelines 
Deformation analysis of deep foundation pit excavation in China under time-space effect

Zhang

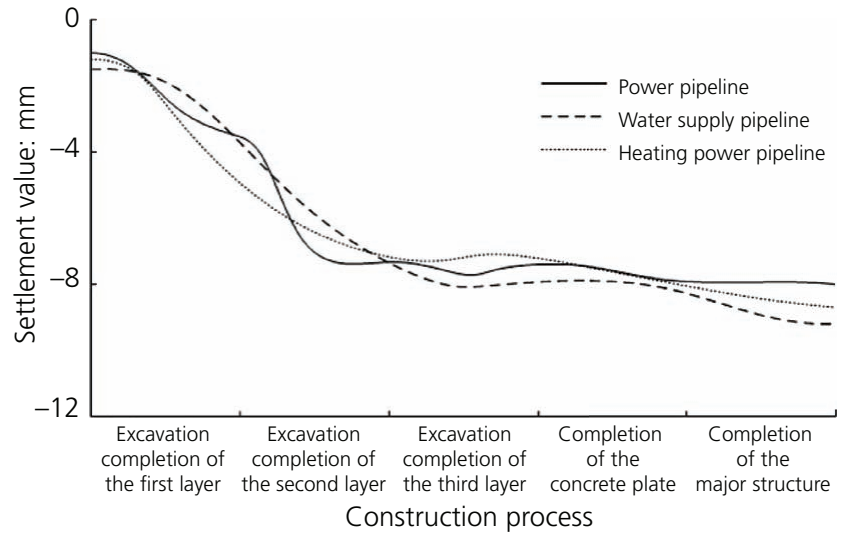

Figure 9. Changes in pipeline settlement with the construction process

were to the pit corner, the smaller the displacement value of the pipelines, and the closer the pipelines were to the middle of the foundation pit, the larger the displacement value of pipelines, which reflected the spatial effect of the pipeline displacement. It is seen from Figure 9 that the settlement value of the pipeline increased gradually with the progress of construction, and the settlement rate was relatively large in the early stage of the project (excavation completion of the first and second layers) and tended to be stable in the later stage of the project.

Table 3. Parameters of the envelope structure

\begin{tabular}{|lccc|} 
& $\begin{array}{c}\text { Diaphragm } \\
\text { wall }\end{array}$ & $\begin{array}{c}\text { Anchor } \\
\text { rod }\end{array}$ & $\begin{array}{c}\text { Inner } \\
\text { support }\end{array}$ \\
\hline Poisson's ratio & 0.18 & 0.18 & 0.18 \\
Unit weight: $\mathrm{kN} / \mathrm{m}^{3}$ & 25 & 75 & 30 \\
Elasticity modulus: $\mathrm{GPa}$ & 30 & 200 & 30
\end{tabular}

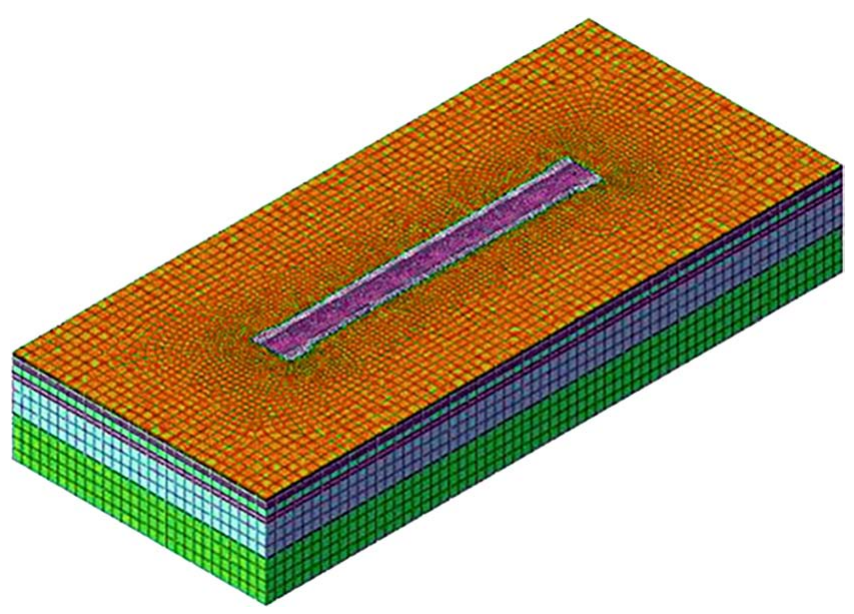

Figure 10. Finite-element model

\section{Finite-element analysis results}

In order to analyse better the deformation of the deep foundation pit, the finite-element analysis of the project was carried out using the $\mathrm{Flac}^{3 \mathrm{D}}$ software. The modified Mohr-Coulomb constitutive model was used, which can effectively reflect the variation tendency of a stratum. The gravity direction was $Z$, and the parameters were default parameters. The soil body was regarded as a homogeneous body with isotropy. The parameters of the soil are shown in Table 1. The parameters of the envelope structure are shown in Table 3. The model size was $380 \times 170 \times 60 \mathrm{~m}$, and it was divided into 232680 units, as shown in Figure 10.

The measured value of the maximum horizontal displacement of the envelope structure was compared with the simulated value of the finite-element analysis, and the results are shown in Figure 11.

It is seen from Figure 11 that the measured value was close to the simulated value, and their variation trends were basically similar. The measured value and simulated value of the maximum horizontal displacement were 13.69 and $11.28 \mathrm{~mm}$, respectively, with a difference of $2.41 \mathrm{~mm}$, but the measured value was basically larger than the simulated value, which might be due to the horizontal displacement being greatly affected by other factors such as the surrounding buildings in the actual project, causing

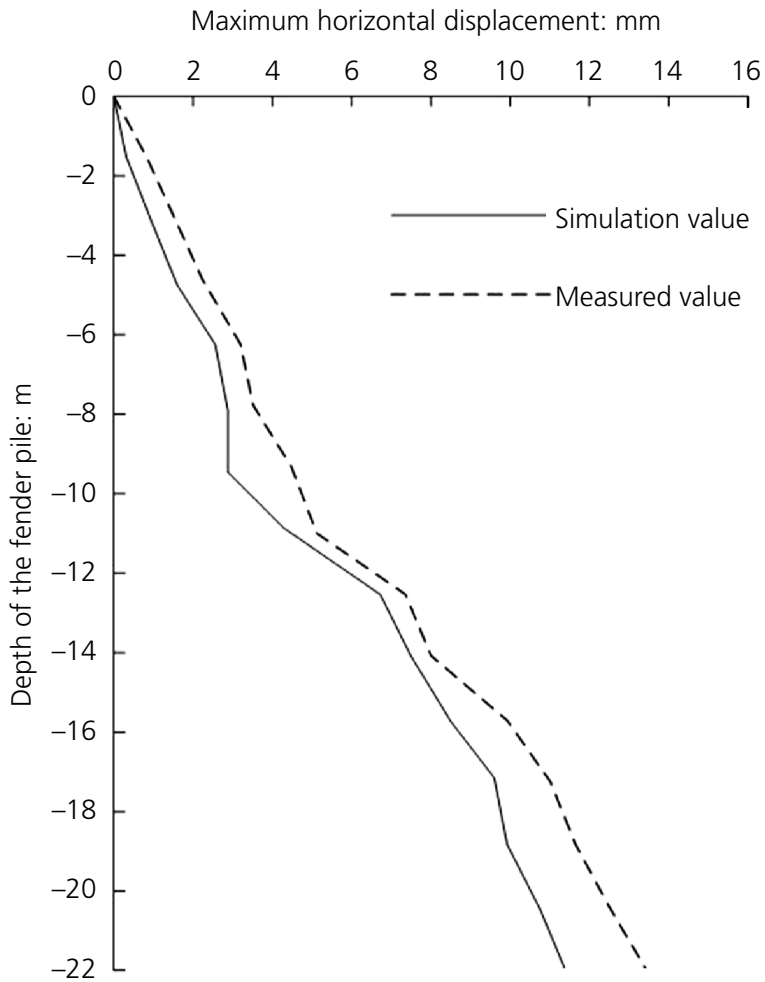

Figure 11. Comparison between measured values and simulated values 
some disturbance to the soil mass. Overall, the result of the finiteelement analysis was reasonable.

\section{Discussion}

In the process of deep foundation pit excavation, the deformation caused by the interference of soil mass is an important problem in the project. This kind of deformation shows different characteristics in different times and different parts. If the deep foundation pit deformation is not mastered enough, it is likely to lead to engineering accidents in the construction process (Yang et al., 2015a). Therefore, the analysis and research of deep foundation pit deformation is of great practical significance and has widely concerned researchers (Zhang et al., 2017b). Technologies such as information management (Xu et al., 2015) and finite-element analysis (Tan et al., 2015; Zhang et al., 2015b) have also been applied in foundation pit research.

In this study, the deformation of a deep foundation pit in Anyang City, China was monitored and analysed. It was found from the monitoring results of the horizontal displacement of the enclosure structure that the displacement value of the enclosure structure gradually increased with the progress of the project, but the displacement value had a large difference between the long side and corner of the enclosure structure. The maximum displacement value at the middle point of the long side was about $13 \mathrm{~mm}$, while that at the corner was only $5 \mathrm{~mm}$, which conformed to the time-space effect. In the process of deep foundation pit excavation, after the excavation of the soil inside the foundation pit, the soil outside the pit began to squeeze, causing the displacement of the enclosure structure, while the corner of the foundation pit had a smaller displacement under the support of the long side and short side and the soil arching effect of the soil. Therefore, in construction engineering, attention should be paid to the support structure of the long side of the foundation pit.

The vertical displacement results of the surrounding buildings showed that the displacement values of different buildings were different but all increased with the progress of the project. Among the three buildings studied, the displacement values of the building near the corner of the foundation pit was significantly smaller than those of the other two buildings on both sides of the foundation pit, which were similar to the displacement results of the enclosure structure, and also showed the effect of time and space.

The settlement results of the surrounding pipelines demonstrated that the closer the pipeline was to the midpoint of the foundation pit, the greater the settlement value of the pipeline, and the farther away it was from the midpoint, the smaller the settlement value of the pipeline. In addition, the settlement value of the pipeline also increased with the progress of the project, showing the effect of time and space; the results of the finite-element analysis also showed similar characteristics. According to the analysis results, some suggestions are put forward for the excavation of a deep foundation pit, in order to make the engineering construction better.

- The exposure time of soil without support should be reduced.
- The width and depth of each excavation should be reduced.

- The rigidity of the enclosure structure should increase appropriately.

- Appropriate distance support and anchor should be set.

- Excavation should be carried out by layers, zones and sections, and overexcavation is prohibited.

- Real-time monitoring of soil state is needed to understand the deformation of the foundation pit.

\section{Conclusion}

The deformation in the process of deep foundation pit excavation is the focus of the project. In this study, a deep foundation pit project in Anyang City, China was taken as an example, and the results showed the following.

- The horizontal displacement of the enclosure structure increased with the advance of the project.

- The maximum displacement of the enclosure structure at the midpoint of the long side was $13 \mathrm{~mm}$, and the maximum displacement at the corner was $5 \mathrm{~mm}$.

- The vertical displacement of the surrounding buildings increased with the advance of the project.

- Compared with the displacement values of other buildings, that of the building near the corner of foundation pit was smaller.

- The settlement value of the surrounding pipeline increased with the advance of the project.

- The closer the pipeline was to the midpoint of the foundation pit, the larger the settlement value, and vice versa.

In the process of excavation, the deep foundation pit shows the characteristics of an obvious time-space effect. Therefore, in the actual project, when designing the support structure, the time-space effect should be fully considered and the excavation should be carried out in layers, zones and sections as far as possible to reduce soil deformation and construction cost. This research provides some theoretical bases for further analysis of the deformation of a deep foundation pit and provides some references for the actual project.

\section{REFERENCES}

Hu J (2017) Research on the influence of excavation of deep foundation pit to adjacent existing high-speed railway bridge pile foundations stability. Journal of Railway Engineering Society 34(6): 12-17 and 22, http://doi.org/10.3969/j.issn.1006-2106.2017.06.003.

Li MG, Zhang ZJ, Chen JJ, Wang JH and Xu AJ (2017) Zoned and staged construction of an underground complex in Shanghai soft clay. Tunnelling and Underground Space Technology 67: 187-200, http:// doi.org/10.1016/j.tust.2017.04.016.

Ong DEL and Choo CS (2011) Sustainable bored pile construction in erratic phyllite. Proceedings of the 2011 ASEAN Australian Engineering Congress, Kuching, Malaysia, pp. 30-45.

Ong DEL, Leung CF and Chow YK (2003a) Piles subject to excavationinduced soil movement in clay. In Geotechnical Problems with Man-made and Man Influenced Grounds: Proceedings of 13th European Conference on Soil Mechanics and Geotechnical Engineering, Prague, Czech Republic, 25-28th August 2003 (Vaníček I (ed.)). Czech Geotechnical Society, Prague, Czech Republic, vol. 2, pp. 777-782. 
Deformation analysis of deep foundation

pit excavation in China under time-space

effect

Zhang
Ong DEL, Leung CF and Chow YK (2003b) Time-dependent pile behaviour due to excavation-induced soil movement in clay. Proceedings of the 12th Pan-American Conference on Soil Mechanics and Geotechnical Engineering, Boston, MA, USA, vol. 2, pp. 2035-2040.

Ong DEL, Yang DQ and Phang SK (2006) Comparison of finite element modelling of a deep excavation using SAGE-CRISP and PLAXIS. Proceedings of the 2006 International Conference on Deep Excavations, Singapore, pp. 51-64.

Tan R, Xu T, Xu W and Zhang Q (2015) Back analysis of soil parameters for deep foundation pit excavation based on artificial neural network. Journal of Hydroelectric Engineering 34(7): 109-117, http://doi.org/ 10.11660/slfdxb.20150714.

Wang L, Luo Z, Xiao J and Juang CH (2014) Probabilistic inverse analysis of excavation-induced wall and ground responses for assessing damage potential of adjacent buildings. Geotechnical and Geological Engineering 32(2): 273-285, http://doi.org/10.1007/s10706-013-9709-4.

Wang J, Liu X, Xiang J, Jiang Y and Feng B (2016) Laboratory model tests on water inrush in foundation pit bottom. Environmental Earth Sciences 75(14): article 1072, https://doi.org/10.1007/s12665-016-5861-5.

Xu W, Tang D, Tan R and Zhang Q (2015) Application of digital foundation pit system in a deep excavation. Chinese Journal of Rock Mechanics and Engineering 34(S1): 3510-3517, https://doi.org/10. 13722/j.cnki.jrme.2014.0246 (in Chinese).

Xu G, Zhang J, Liu H and Ren C (2017) Shanghai center project excavation induced ground surface movements and deformations. Frontiers of Structural and Civil Engineering 12(1): 26-43, https://doi.org/10. 1007/s11709-017-0439-1.

Yang Q, Liu Y, Wang Y and Tang X (2015a) Analysis of and treatment technologies for a piping accident in the deep foundation pit of a shield tunnel. Modern Tunnelling Technology 52(4): 184-189 and 200, https://doi.org/10.13807/j.cnki.mtt.2015.04.027 (in Chinese).

Yang TL, Yan XX, Wang HM, Huang XL and Zhan GH (2015b) Comprehensive experimental study on prevention of land subsidence caused by dewatering in deep foundation pit with hanging waterproof curtain. Proceedings of IAHS 372: 1-5, https://doi.org/10.5194/piahs372-1-2015.

Ye SH, Ding SH, Gong XN, Gao S and Chen CL (2018) Monitoring and numerical simulation of deep foundation pit of a subway station in Lanzhou. Chinese Journal of Geotechnical Engineering 40(S1): 177-182, https://doi.org/10.11779/CJGE2018S1029.

Zhang $X$ and Liu $Y$ (2018) Influence of soil parameters on deformation of retaining structure of deep foundation pit. Journal of Liaoning Technical University (Natural Science Edition) 37(5): 794-798, https:// doi.org/10.11956/j.issn.1008-0562.2018.05.005 (in Chinese).

Zhang J, Zhang L and Zhang S (2015a) A study on deformation characteristics of foundation pit for Xuzhou metro station near the river. China Civil Engineering Journal 48(10): 113-117 (in Chinese).

Zhang Z, Xu C, Liu M and Wang W (2015b) Deformation analysis of metro tunnels considering impacts of dewatering excavation in foundation pit engineering. Journal of China University of Mining and Technology 44(2): 241-248 (in Chinese).

Zhang Z, Zhang M and Zhao Q (2015c) A simplified analysis for deformation behavior of buried pipelines considering disturbance effects of underground excavation in soft clays. Arabian Journal of Geosciences 8(10): 7771-7785, https://doi.org/10.1007/s12517-0141773-4.

Zhang Z, Zhao Q and Lu M (2015d) Analysis on settlement monitoring of historical protective buildings adjacent to deep foundation pit excavation. China Civil Engineering Journal 48(S2): 137-142 (in Chinese).

Zhang W, Zhang Y and Goh ATC (2017a) Multivariate adaptive regression splines for inverse analysis of soil and wall properties in braced excavation. Tunnelling and Underground Space Technology 64 24-33, https://doi.org/10.1016/j.tust.2017.01.009.

Zhang Z, Bai Q, Jiang Y and Wang W (2017b) In-situ monitoring analyses of the influences of deep foundation pit excavation on adjacent metro tunnels and surrounding strata. Modern Tunnelling Technology 54(2): 177-184, https://doi.org/10.13807/j.cnki.mtt.2017.02.025 (in Chinese).

\section{How can you contribute?}

To discuss this paper, please submit up to 500 words to the editor at journals@ice.org.uk. Your contribution will be forwarded to the author(s) for a reply and, if considered appropriate by the editorial board, it will be published as a discussion in a future issue of the journal. 